\title{
Pesquería artesanal de pez espada y temperatura superficial del mar registrada con satélites NOAA en Chile central*
}

\author{
Eleuterio Yáñez R. ${ }^{1}$, Claudio Silva G. ${ }^{1}$, María Angela Barbieri B. ${ }^{1,2}$ y Karen Nieto S. ${ }^{1}$ \\ ${ }^{1}$ Escuela de Ciencias del Mar, Universidad Católica de Valparaíso \\ Casilla 1020, Valparaíso, Chile \\ ${ }^{2}$ Instituto de Fomento Pesquero, Casilla 8-V, Valparaíso, Chile
}

RESUMEN. En Chile central el pez espada (Xiphias gladius) se distribuye más bien en ciertas temperaturas de aguas de origen oceánico, que en discontinuidades térmicas que se forman entre éstas y las frías más costeras. Estas características de la superficie del mar (TSM) se visualizan en las imágenes de TSM confeccionadas con datos de satélites NOAA, a pesar del problema que provoca la presencia de nubes.

Palabras claves: pez espada, pesquería artesanal, CPUE, satélites NOAA, TSM, Chile central.

\section{Artisanal swordfish fishery and sea surface temperatures from NOAA satellites in central Chile*}

\begin{abstract}
The swordfish (Xiphias gladius) in Chile's central zone is associated to certain temperatures from waters of oceanic origin rather than to thermal discontinuities formed between them and the shoreward waters. These features of the sea surface are visualized from the temperature (SST) images produced from NOAA satellite data, in spite of the cloud contamination problem.
\end{abstract}

Key words: swordfish, artisanal fishery, CPUE, NOAA satellite, SST, central Chile.

\section{INTRODUCCION}

En Chile la pesquería de pez espada (Xiphias gladius) ha sido realizada tradicionalmente por pescadores artesanales, con registros de captura disponibles desde 1938 (Barbieri et al., 1990). El nuevo impulso de la pesquería observado a partir de 1986 (Tabla 1), se relaciona con la apertura del mercado internacional, el cual genera una importante demanda por esta especie. Esto implicó el ingreso de la flota palangrera industrial y un crecimiento importante de la flota de lanchas artesanales; éstas aumentaron en tamaño e incorporaron mejoras en los equipos de navegación y posicionamiento, y la red de enmalle de deriva como sistema de pesca (Yáñez et al., 1994). Además se incorporó el empleo de imágenes satelitales de temperatura superficial del mar, mejorando la capacidad de prospección de la flota artesanal (Barbieri et al., 1995/96).

En el país, la pesquería de pez espada estuvo sujeta al régimen de libre acceso hasta 1990. Desde 1991 se establecen medidas de manejo asociado a la regulación de artes y áreas de pesca, al control del acceso de nuevas naves a la pesquería y a la declaración de ésta en estado de plena explotación. Así, en el período 1985-95 el desembarque total anual aumenta hasta 1991, y luego presentan una inquietante tendencia a la disminución (Tabla 1), afectando las exportaciones (Tabla 2). Las evaluaciones muestran una disminución razonable de la captura por unidad de esfuerzo (CPUE) hasta 199091, asociada a un importante aumento de esfuerzo de pesca y de las capturas; sin embargo, el posterior

* Proyecto SATAL II, Grant UCV (Chile) - CIID (Canadá): Centre File 92-0610.

Presentado en el Second International Pacific Swordfish Symposium, 3-6 Mars '96, Hawai. 
aumento del esfuerzo de pesca implica disminuciones simultáneas de la CPUE y de los desembarques, lo cual indicaría un cierto grado de sobreexplotación del recurso (Yáñez et al., 1994).

Cabe hacer notar que este aumento del esfuerzo de pesca se asocia a un alejamiento de las zonas de pesca. Hasta 1989 la flota artesanal realizaba sus faenas dentro de las 90 millas náuticas (mn) de la costa, en tanto que desde 1990 la explotación alcanza las $200 \mathrm{mn}$, distancia que es sobrepasada ocasionalmente (González, 1993; Barbieri et al., 1995/ 96). Este alejamiento ha creado problemas a las lanchas artesanales, particularmente a las de menor autonomía, lo cual explicaría en alguna medida la disminución de los índices en los últimos años (Tabla 3).

En este trabajo se analiza la distribución espacial de los rendimientos de pez espada de la flota artesanal en Chile central, asociada a la temperatura superficial del mar registrada con satélites NOAA, con el propósito de consolidar el uso de esta tecnología en la búsqueda de zonas probables de pesca.

\section{MATERIALES Y METODOS}

\section{Información analizada}

La zona de estudio se ubica entre $\operatorname{los} 31^{\circ}$ y $36^{\circ} \mathrm{S}$, desde la costa hasta los $76^{\circ} \mathrm{W}$, contemplando las temporadas de pesca de lanchas artesanales realizadas

Tabla 1. Desembarques anuales (t) de pez espada en Chile y en el Pacífico Sur Oriental.

Table 1. Annual landings ( $t$ ) of swordfish in Chile and South Eastern Pacific.

\begin{tabular}{|c|c|c|c|c|}
\hline Años & $\begin{array}{c}\text { Desembarque } \\
\text { artesanal } \\
\text { en Chile }\end{array}$ & $\begin{array}{c}\text { Desembarque } \\
\text { industrial } \\
\text { en Chile }\end{array}$ & $\begin{array}{c}\text { Desembarque } \\
\text { total } \\
\text { en Chile }\end{array}$ & $\begin{array}{c}\text { Desembarque } \\
\text { en el Pacífico } \\
\text { Sur Oriental }\end{array}$ \\
\hline 1985 & 342 & 0 & 342 & 688 \\
1986 & 747 & 17 & 764 & 1.239 \\
1987 & 1.869 & 190 & 2.059 & 2.662 \\
1988 & 3.972 & 483 & 4.455 & 5.508 \\
1989 & 4.741 & 1.083 & 5.824 & 6.318 \\
1990 & 3.850 & 1.015 & 4.955 & 6.072 \\
1991 & 3.286 & 3.969 & 7.255 & 8.398 \\
1992 & 2.801 & 3.578 & 6.379 & 7.777 \\
1993 & 2.733 & 1.979 & 4.712 & 5.481 \\
1994 & 2.552 & 1.249 & 3.801 & sin infor. \\
1995 & 2.085 & 509 & 2.594 & sin infor. \\
\hline
\end{tabular}

Fuente: SERNAP (1985-95); FAO, Area 87 (1985-93). durante 1994 y 1995 (Fig. 1). Cabe señalar que más del $60 \%$ de los desembarques artesanales de pez espada se realizan en los puertos de la $\mathrm{V}$ Región $\left(32^{\circ}-34^{\circ} \mathrm{S}\right)$, salvo en 1994 en que fueron sobrepasados por los efectuados en la VIII Región $\left(36^{\circ}-38^{\circ} \mathrm{S}\right)$ (Tabla 4).

La información sobre capturas $(\mathrm{t})$ y lugar de procedencia, con una resolución espacial de 10x10 mn, fue recolectada del accionar de lanchas artesanales que desembarcaron en los puertos de la zona de estudio (Fig. 1). De este modo se recolectaron un total de 375 fichas en 1994 y 211 en 1995; de éstas, respectivamente $84 \%$ y $73 \%$ corresponden a lanchas que desembarcaron en los puertos de Valparaíso y San Antonio, y el resto en los puertos de Quintero y Constitución, y en la caleta El Quisco. Cabe señalar que en 1995 la flota artesanal se desplazó hacia el norte de la zona de estudio a partir de junio, desembarcando mayoritariamente en el puerto de Coquimbo (30 $\mathrm{S})$ (IFOP, 1996).

También se realizaron observaciones a bordo con el objeto de precisar el régimen operacional y los lugares de pesca, además de registrar in situ la temperatura superficial del mar (TSM), para contrastarla como es habitual con la TSM registrada con satélites NOAA ( $\mathrm{r}=85 \%$, con 65 pares de valores de igual georreferencia).

La información satelital de TSM proviene del sensor AVHRR de satélites NOAA, recibida y decodificada por el Centro de Estudios Espaciales (CEE) de la Universidad de Chile y el Centro de Percepción Remota de la Pontificia Universidad Católica de Chile, desde donde es transmitida al Laboratorio de Percepción Remota de la Universidad Católica de Valparaíso. Para la zona de estudio dicha información representa matrices de datos de TSM de 570 columnas por 600 filas, con una resolución espacial de 2,2 $\mathrm{km}$ en el sentido $\mathrm{N}-\mathrm{S}$ y $1,6 \mathrm{~km}$ en el sentido E-W, en una escala de 1:2.000.000.

\section{Tratamiento de la información}

Para analizar la distribución del pez espada se empleó el índice de densidad captura por unidad de esfuerzo (CPUE=kg/dm); es decir, la captura $(\mathrm{kg})$ dividida por los días en el mar 
Tabla 2. Valor de las exportaciones del pez espada explotado en Chile.

Table 2. Exports value of swordfish exploited in Chile.

\begin{tabular}{|c|c|c|c|}
\hline Años & $\begin{array}{c}\text { Exportación } \\
(\mathrm{t})\end{array}$ & $\begin{array}{c}\text { US\$-FOB } \\
\text { (miles) }\end{array}$ & US\$/t \\
\hline 1986 & 695 & 3.800 & 5.468 \\
1987 & 1.619 & 11.300 & 6.980 \\
1988 & 2.723 & 18.800 & 6.904 \\
1989 & 4.563 & 28.000 & 6.136 \\
1990 & 4.672 & 25.300 & 5.415 \\
1991 & 5.999 & 39.300 & 6.551 \\
1992 & 4.751 & 36.000 & 7.577 \\
1993 & 3.757 & 28.776 & 7.659 \\
1994 & 3.063 & 22.763 & 7.432 \\
1995 & 2.567 & 21.275 & 8.288 \\
\hline
\end{tabular}

Fuente: IFOP-Aduana.

Tabla 3. Desembarques, esfuerzos de pesca y CPUE anules de pez espada en Chile.

Table 3. Annual landings, fishing efforts and CPUE of swordfish in Chile.

\begin{tabular}{|l|c|c|c|}
\hline Años & $\begin{array}{c}\text { Desembarque } \\
\text { total }(\mathrm{t})\end{array}$ & $\begin{array}{c}\text { Esfuerzo } \\
\text { total }(\mathrm{dm})^{*}\end{array}$ & $\begin{array}{c}\text { CPUE } \\
(\mathrm{kg} / \mathrm{dm})\end{array}$ \\
\hline 1987 & 2.059 & 5.265 & 391 \\
1988 & 4.455 & 17.200 & 259 \\
1989 & 5.824 & 20.152 & 289 \\
1990 & 4.955 & 18.150 & 273 \\
1991 & 7.255 & 38.215 & 185 \\
1992 & 6.379 & 37.305 & 171 \\
1993 & 4.712 & 40.974 & 115 \\
1994 & 3.801 & 38.786 & 98 \\
1995 & 2.594 & 29.477 & 88 \\
\hline
\end{tabular}

* medido en días en el mar de lanchas artesanales.

(dm). Los dm incluyen tiempos de navegación sin incidencia directa sobre el stock, que se recomienda eliminar; sin embargo, esto es posible con información precisa sobre los tiempos de operación, dado que los desplazamientos también cubren un esfuerzo de localización de los mejores lugares de pesca (Laurec y Le Guen, 1981).

En marzo-agosto de 1994 las lanchas desarrollaron mareas de un promedio de $9,1 \pm 3,5 \mathrm{dm}$ y en

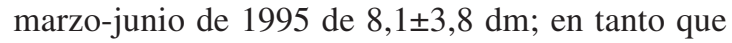
en los lugares de pesca realizan normalmente un lance por noche. Como en general no se presentan diferencias significativas entre la CPUE promedio mensual de lanchas de diferentes esloras (11-18 m), no se considera necesario estandarizar el esfuerzo de pesca de esta flota (Yánez et al., 1994). Luego, la CPUE promedio de las (NB) lanchas, en la cuadrícula (n) y en el tiempo (t), es estimada del siguiente modo:

$$
C P U E_{i=1}^{N B}=\left(\sum(k g / d m)_{\text {int }}\right) / N B
$$

Por otra parte, con el Sistema de Información Geográfica (SIG) IDRISI (Eastman, 1995), se georreferenció la costa y el centro de las cuadrículas de 10x10 mn que componen la zona de estudio, en coordenadas latitud/longitud. Luego se confeccionan cartografías anuales, mensuales y semanales con la ubicación de las CPUE promedio correspondientes, con el objeto de analizar por superposición la distribución de este índice con las imágenes de TSM de la zona de estudio confeccionadas con datos de satélites NOAA.

La información satelital recibida es georrerefenciada y procesada con el programa MUESTRE-4 del CEE de la Universidad de Chile y el SIG IDRISI, creando imágenes diarias de TSM de la zona de estudio. Para una mejor visualización se considera la confección de imágenes de TSM en pseudo-color, representando valores enteros de temperatura (cada $1^{\circ} \mathrm{C}$ ) con un determinado color.

Cabe señalar que el uso de información de satélites NOAA presenta problemas cuando la zona de estudio se encuentra cubierta por nubes (Maravelias y Reid, 1995; Barbieri et al., 1995, 1995/96). Para reducir el efecto de las nubes que se registran en las imágenes de TSM diarias, en el análisis de la estructura térmica superficial se puede considerar el valor máximo de la TSM de los diferentes pixeles que componen la cuadrícula (TSMM) (Pettigiani et al., 1992; Yánez et al., 1995).

Así, con el SIG IDRISI se superponen las imágenes diarias disponibles creando imágenes mensuales de TSMM. Este mismo proceder se ocupó para crear imágenes de TSMM semanales cuando se disponía de más de una imagen por semana, como ocurrió para el período abril-junio de 1995; para el período marzo'94-marzo'95 se dispuso de una imagen por semana. Luego, por superposición de las imágenes mensuales se crean cartas promedios anuales de TSMM, cubriendo con una máscara la contaminación de nubes que persiste.

Por otra parte, con el mismo SIG se determinan la $\mathrm{TSMM}_{\mathrm{ns}}$ y el gradiente término $\left(\mathrm{GRT}_{\mathrm{ns}}=\right.$ máxima 
Tabla 4. Desembarque artesanal de pez espada (t/año) en la V y VIII Región, y porcentaje sobre el total del sector.

Tabla 4. Artisanal landing of swordfish (t/year) in the V and VIII Región, and percentage of the total sector.

\begin{tabular}{|l|r|r|r|}
\hline Años & $\begin{array}{c}\text { Desembarque } \\
\text { V Región }\end{array}$ & $\begin{array}{c}\text { Desembarque } \\
\text { VIII Región }\end{array}$ & $\begin{array}{c}\text { Desembarque } \\
\text { V-VIII Región }\end{array}$ \\
\hline 1987 & $1.827(98 \%)$ & $0(0 \%)$ & $1.827(98 \%)$ \\
1988 & $3.035(76 \%)$ & $200(5 \%)$ & $3.235(81 \%)$ \\
1989 & $3.229(68 \%)$ & $773(16 \%)$ & $4.002(84 \%)$ \\
1990 & $2.764(72 \%)$ & $574(15 \%)$ & $3.338(87 \%)$ \\
1991 & $2.191(67 \%)$ & $690(21 \%)$ & $2.881(88 \%)$ \\
1992 & $1.808(65 \%)$ & $840(30 \%)$ & $2.648(95 \%)$ \\
1993 & $1.650(61 \%)$ & $701(25 \%)$ & $2.351(86 \%)$ \\
1994 & $799(31 \%)$ & $1.127(44 \%)$ & $1.926(75 \%)$ \\
1995 & $1.506(72 \%)$ & $312(15 \%)$ & $1.818(87 \%)$ \\
& & & \\
\hline
\end{tabular}

Fuente: SERNAP (1987-95).

diferencia de TSM) de la cuadrícula con pesca (n) en la semana (s). En los casos de presencia de nu-

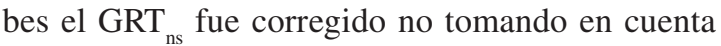
los pixeles contaminados, o simplemente eliminando dicha cuadrícula del análisis cuando la cantidad de pixeles contaminados era muy importante. Finalmente se analizan las $\mathrm{CPUE}_{\mathrm{ns}}$ y los estimados correspondientes de TSMM $_{\text {ns }}$ y GTR $_{\text {ns }}$. Cabe señalar que prácticamente el mismo enfoque metodológico fue empleado por Power y May (1991), Reddy et al. (1995) y Yáñez et al. (1996).

\section{RESULTADOS Y DISCUSIÓN}

En la V Región los desembarques de pez espada se realizan normalmente durante todo el año, pero con mayor intensidad en marzo-agosto (Tabla 5). Cabe señalar que los desembarques del período junio-diciembre de 1995 corresponden esencialmente al sector industrial; en esta época la flota artesanal se desplazó al norte de la zona de estudio, desembarcando en el puerto de Coquimbo $\left(30^{\circ} \mathrm{S}\right)$.

En la Fig. 1 se observa que la distribución del pez espada, durante las temporadas de pesca de 1994 y 1995 en la zona de estudio, se asociaría más bien a ciertas temperaturas que a discontinuidades térmicas que se forman entre las aguas oceánicas y las frías más costeras, donde sí se concentran el atún aleta larga (Thunnus alalunga) (Barbieri et al., 1987; Bakun, 1994), y el jurel (Trachurus murphyi) (Yáñez et al., 1996).

En efecto, al inicio de la temporada de pesca el pez espada se encuentra cerca de la costa en aguas relativamente cálidas (Fig. 2 y 3), donde es incluso capturado con arpón (Yáñez et al., 1994). Luego el recurso se aleja de la costa en la medida que se desarrolla el proceso de enfriamiento; éste se magnifica durante 1995, afectando la disponibilidad del recurso y por ende un accionar de la flota al norte de la zona de estudio durante julio y agosto (Fig. 3).

A pesar del tratamiento de la información satelital, las cartografías de TSMM de julio y agosto de 1994 muestran todavía efectos de contaminación por nubes (Fig. 2). Para este año se consideró el empleo de un menor número de imágenes diarias de TSM por mes: 4 en marzo, 3 en abril, 3 en mayo, 4 en junio, 2 en julio y 2 en agosto. Para la temporada de 1995 tal problema no se aprecia (Fig. 3), debido al uso de un mayor número de imágenes diarias de TSM: 5 en marzo, 9 en abril, 8 en mayo y 5 en junio.

A continuación se presentan ejemplos de distribuciones espaciales (semanal/mes) de CPUE de pez espada, sobre imágenes diarias de TSM disponibles para las semanas correspondientes de 1994 (Fig. 4) y de 1995 (Fig. 5). De las imágenes así configuradas se determinaron para cada una de las cuadrículas con pesca, la CPUE ${ }_{\text {ns }}$ con sus TSMM ns $_{\text {GTR }}$ correspondientes; posteriormente se eliminaron del análisis las cuadrículas total o demasiado contaminadas con nubes.

Durante marzo-agosto de 1994 el pez espada se capturó entre $14^{\circ}$ y $20^{\circ} \mathrm{C}$, pero principalmente entre $14^{\circ}$ y $18^{\circ} \mathrm{C}$, con una importante dispersión entre altos y bajos rendimientos (Fig. 6a); ésta distribución se clarifica al considerar los períodos marzo-mayo (Fig. 6b) y junio-agosto (Fig. 6c). Los registros de CPUE asociados a TSM de $12-14^{\circ} \mathrm{C}$, similares a los rendimientos más bajos del período marzo-mayo, fueron eliminados; esto debido al complicado problema de contaminación de nubes, observado particularmente en julio y agosto del '94 (Fig. 4). No obstante, cabe señalar que a nivel mundial el pez espada es capturado entre 10 y $25^{\circ} \mathrm{C}$ (OPI Inc., 1994).

Los bajos rendimientos logrados entre $18^{\circ}$ y $20^{\circ} \mathrm{C}$ en 1994, corresponden a la información de marzo y abril (Fig. 7). Posteriormente, al paso del enfriamiento general (Fig. 4), aparecen rendimientos que sobrepasan los $150 \mathrm{~kg} / \mathrm{dm}$ principalmente en mayo 


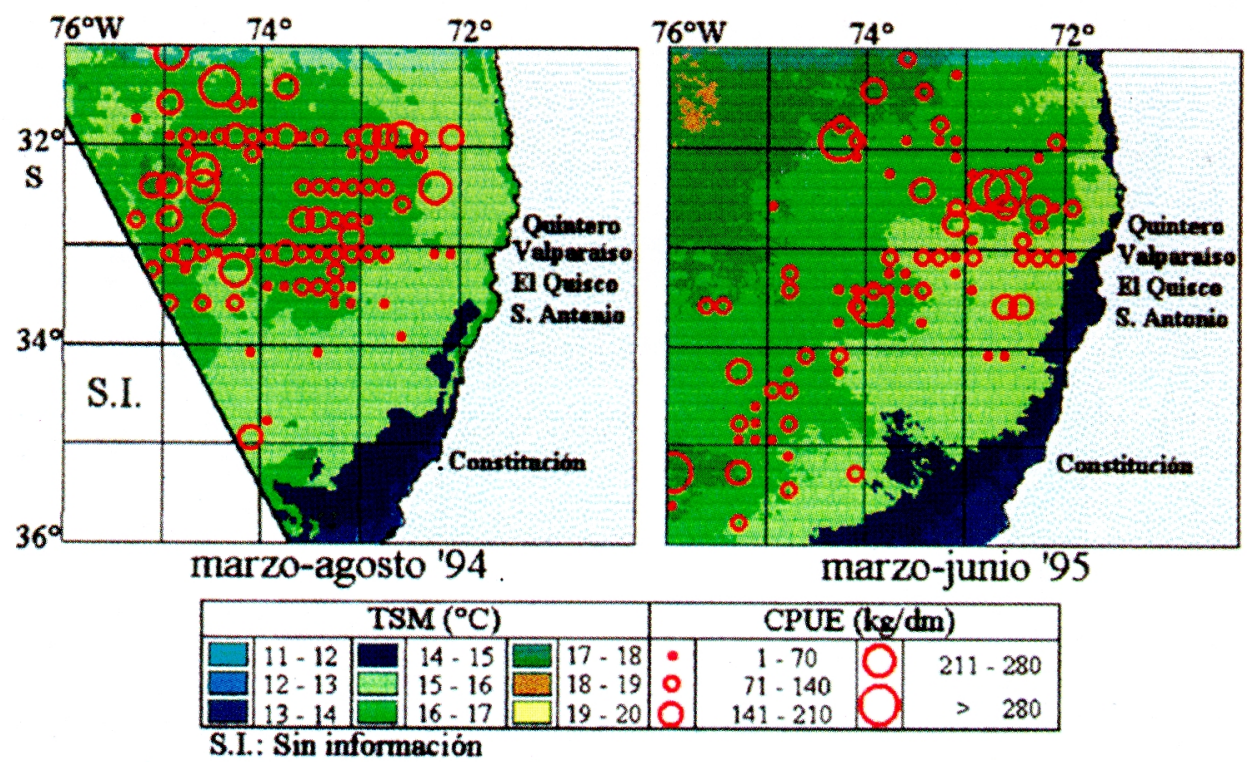

Figura 1. Distribución de la CPUE (kg/dm) y TSMM $\left({ }^{\circ} \mathrm{C}\right)$ durante marzo-agosto 1994 y marzo-junio 1995.

Figure 1. CPUE (kg/sea day) and MSST $\left({ }^{\circ} \mathrm{C}\right)$ distribution during March-August 1994 and March-June 1995.

Tabla 5. Desembarques (t) mensuales de pez espada en la V Región.

Table 5. Monthly landings (t) of swordfish in the $\mathrm{V}$ Region.

\begin{tabular}{|l|r|r|r|r|}
\hline Meses & 1992 & 1993 & 1994 & 1995 \\
\hline Enero & 3 & 0 & 6 & 0 \\
Febrero & 14 & 20 & 1 & 4 \\
Marzo & 114 & 245 & 78 & 33 \\
Abril & 436 & 392 & 64 & 163 \\
Mayo & 906 & 704 & 125 & 427 \\
Junio & 718 & 335 & 311 & 416 \\
Julio & 922 & 325 & 323 & 189 \\
Agosto & 107 & 32 & 131 & 138 \\
Septiembre & 30 & 41 & 24 & 103 \\
Octubre & 28 & 2 & 0 & 71 \\
Noviembre & 13 & 4 & 0 & 67 \\
Diciembre & 19 & 0 & 0 & 23 \\
\hline
\end{tabular}

Fuente: SERNAP (1992-95).

$\left(16^{\circ}-18^{\circ} \mathrm{C}\right)$, y junio $\left(14^{\circ}-17^{\circ} \mathrm{C}\right)$, disminuyendo en proporción en julio y agosto $\left(14^{\circ}-16^{\circ} \mathrm{C}\right)$.

Durante marzo-junio de 1995 las capturas se realizaron entre $15^{\circ}$ y $19,5^{\circ} \mathrm{C}$, observándose una dispersión y una disminución de los rendimientos (Fig. 8), en comparación con la temporada de pesca de 1994 (Fig. 6a). Mensualmente éstos se realizan en los $17^{\circ}-19,5^{\circ} \mathrm{C}$ en marzo, $16^{\circ}-19^{\circ} \mathrm{C}$ en abril, y $15^{\circ}-$ $19^{\circ} \mathrm{C}$ en mayo-junio (Fig. 9). En junio la información es menos importante, debido al inicio de la migración de la flota al norte de la zona de estudio, donde operó en julio y agosto (Fig. 3).

Durante la temporada de pesca de 1994 la flota logra sus rendimientos en gradientes de 0,2 a $1,7^{\circ} \mathrm{C}$, con una cierta tendencia a la disminución (Fig. 10a). Los valores superiores a $150 \mathrm{~kg} / \mathrm{dm}$ se logran en mayo-junio y los inferiores a $150 \mathrm{~kg} / \mathrm{dm}$ durante toda la temporada de pesca (marzo-agosto). Durante marzo-junio de 1995 la flota operó en áreas con gradientes de $1^{\circ}$ a $3,5^{\circ} \mathrm{C}$, asociados probablemente al mayor enfriamiento de este año, lo cual explicaría en parte la baja en los rendimientos superiores a 150 t/dm (Fig. 10b). En la misma zona los rendimientos de jurel, de enero a septiembre de 1995 , presentan una notable relación positiva con los gradientes térmicos $(\mathrm{R} 2=0,53)$, lográndose los valores más altos entre $2,5^{\circ}$ y $4,5^{\circ} \mathrm{C}$ (Yáñez et al., 1996).

De acuerdo con Yánez et al. (1994), en cerca del $60 \%$ de los estómagos de pez espada capturados en la zona de estudio se encontraron individuos enteros de jurel (Trachurus murphyi) y de merluza de cola (Macruronus magellanicus) del mismo tamaño. En menos del 15\% de éstos se identificaron individuos de camarón nailon (Heterocarpus reedi) 

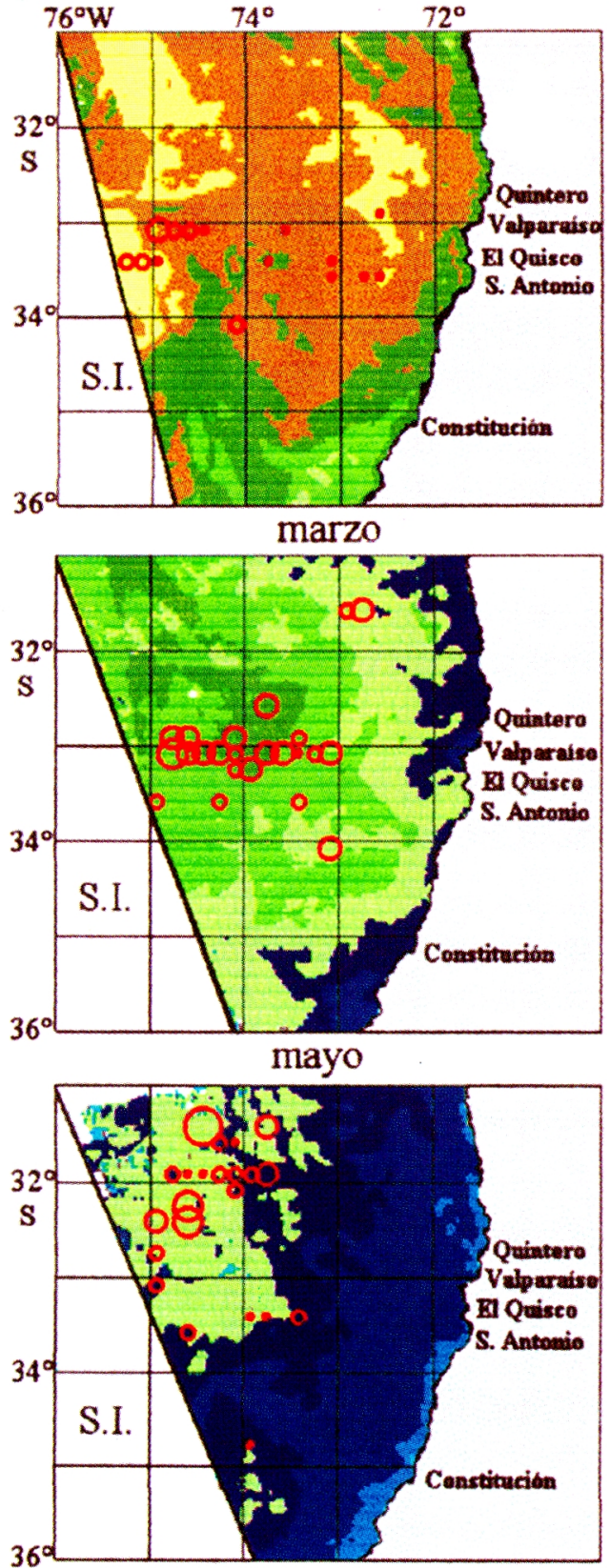

julio

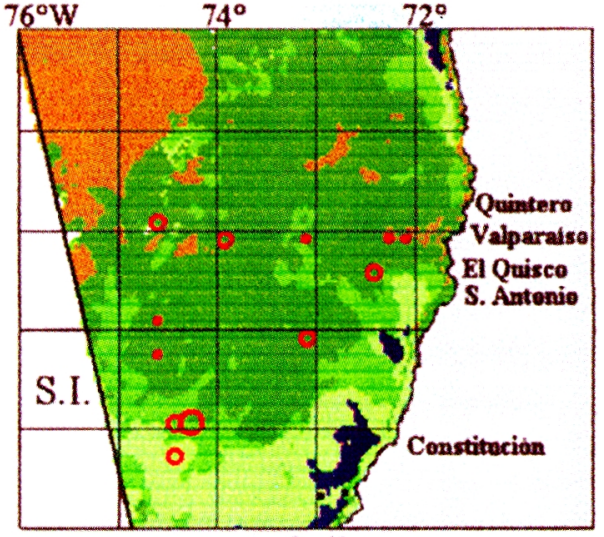

abril

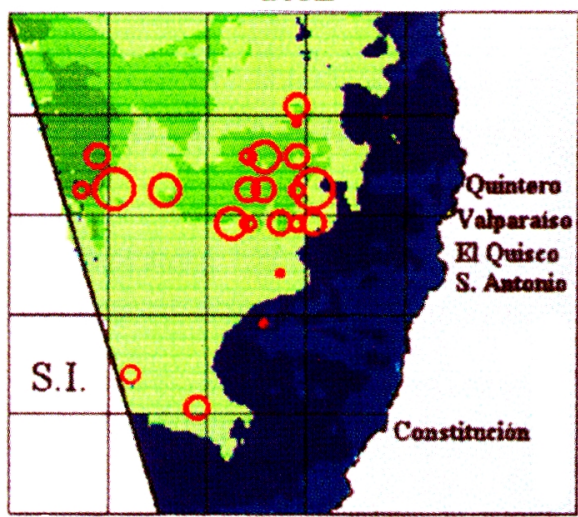

junio

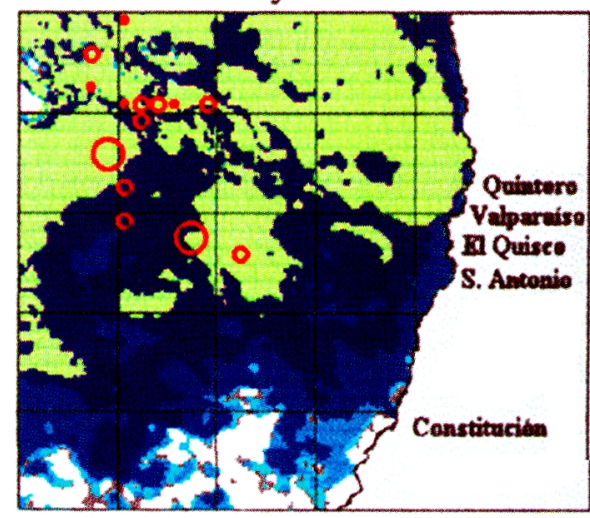

agosto

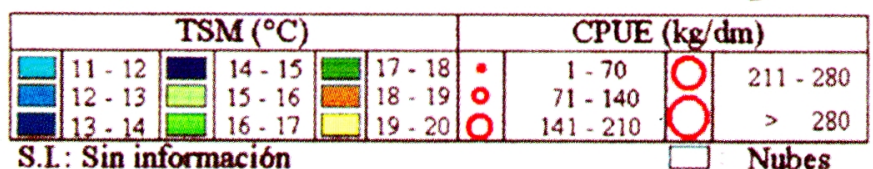

Figura 2. Distribución mensual de la CPUE (kg/dm) y TSMM $\left({ }^{\circ} \mathrm{C}\right)$ durante marzo-agosto 1994. Figure 2. Monthly CPUE (kg/sea day) and MSST $\left({ }^{\circ} \mathrm{C}\right)$ distribution during March-August 1994. 


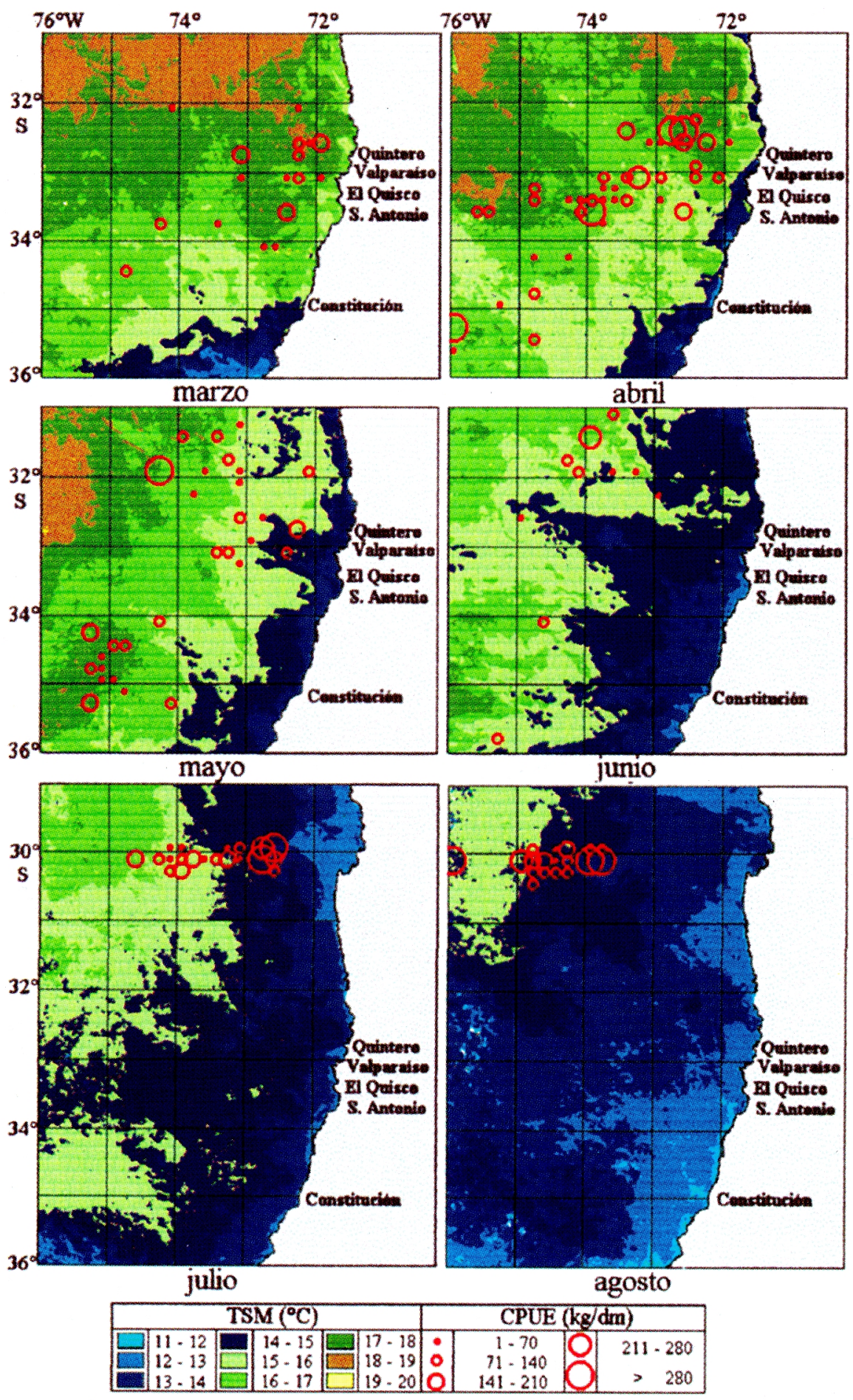

Figura 3. Distribución mensual de la CPUE (kg/dm) y TSMM $\left({ }^{\circ} \mathrm{C}\right)$ durante marzo-agosto 1995. Figure 3. Monthly CPUE (kg/sea day) and MSST $\left({ }^{\circ} \mathrm{C}\right)$ distribution during March-August 1995. 

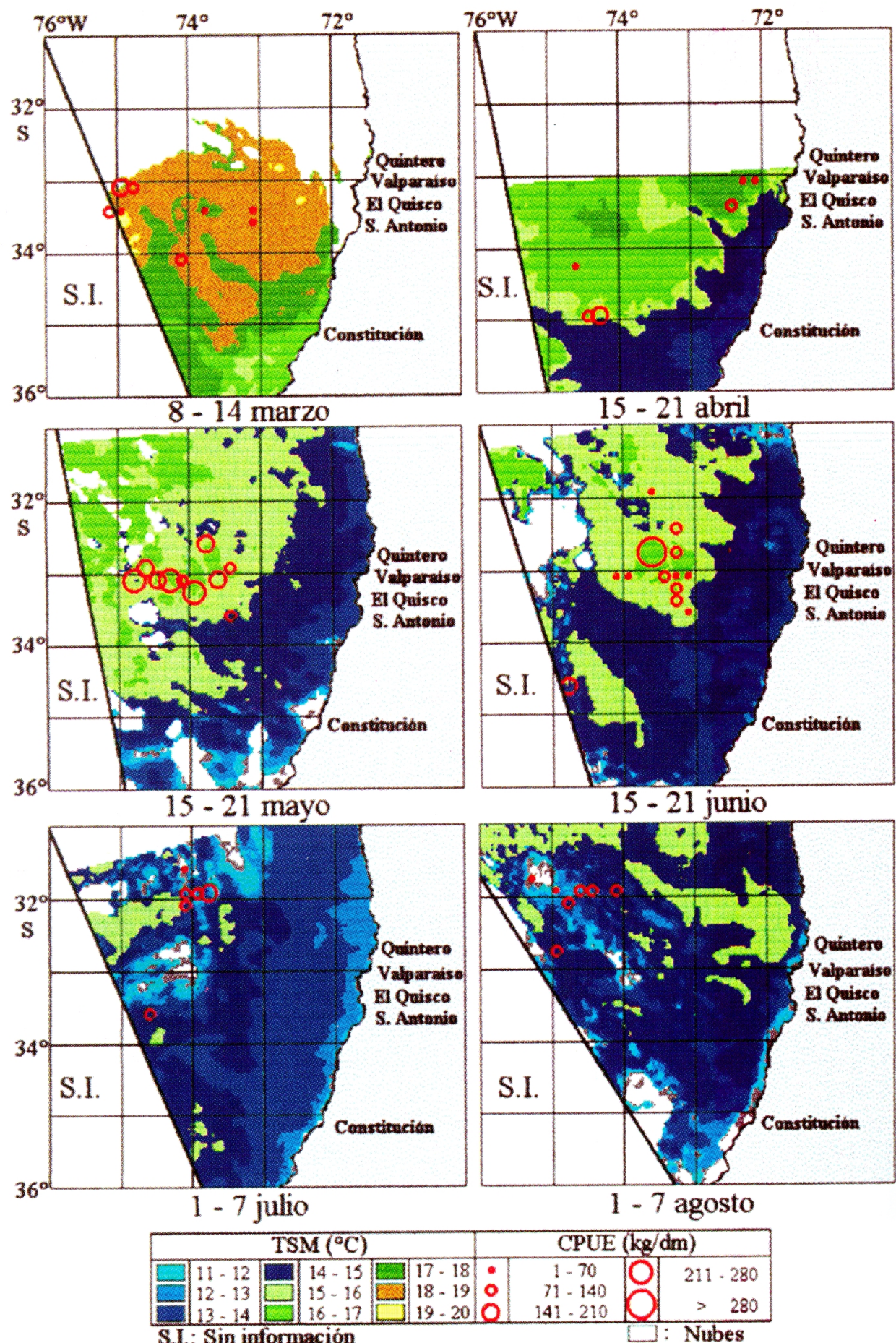

Figura 4. Ejemplos de distribuciones (semana/mes) de CPUE $(\mathrm{kg} / \mathrm{dm})$ y TSM $\left({ }^{\circ} \mathrm{C}\right)$ durante marzo-agosto 1994. Figure 4. Examples of CPUE (kg/sea day) and SST $\left({ }^{\circ} \mathrm{C}\right)$ distributions (week/month) during March-August 1994. 


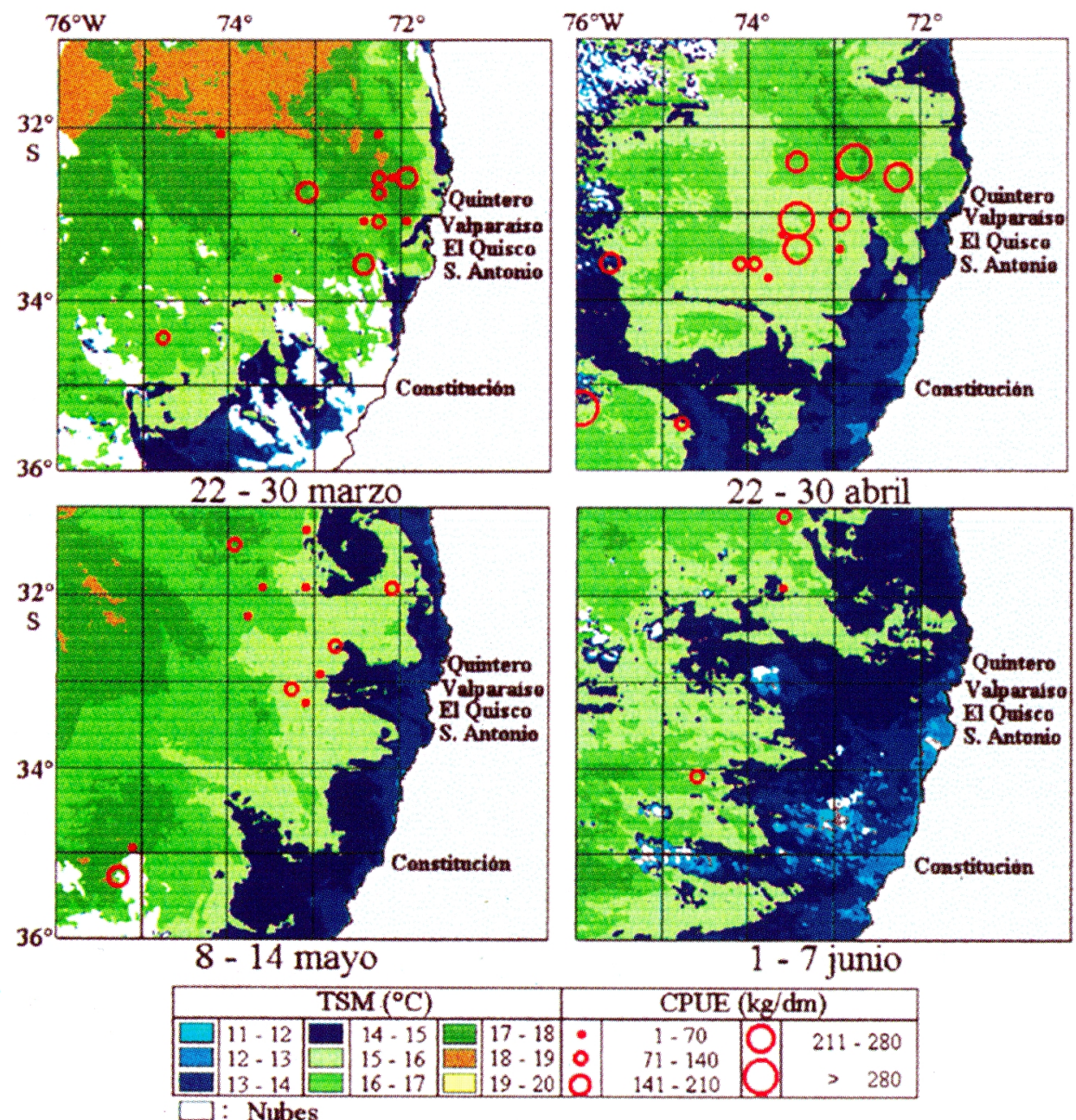

Figura 5. Ejemplos de distribuciones (semana/mes) de CPUE (kg/dm) y TSM $\left({ }^{\circ} \mathrm{C}\right)$ durante marzo-junio 1995. Figure 5. Examples of CPUE (kg/sea day) and SST $\left({ }^{\circ} \mathrm{C}\right)$ distributions (week/month) during March-June 1995. 

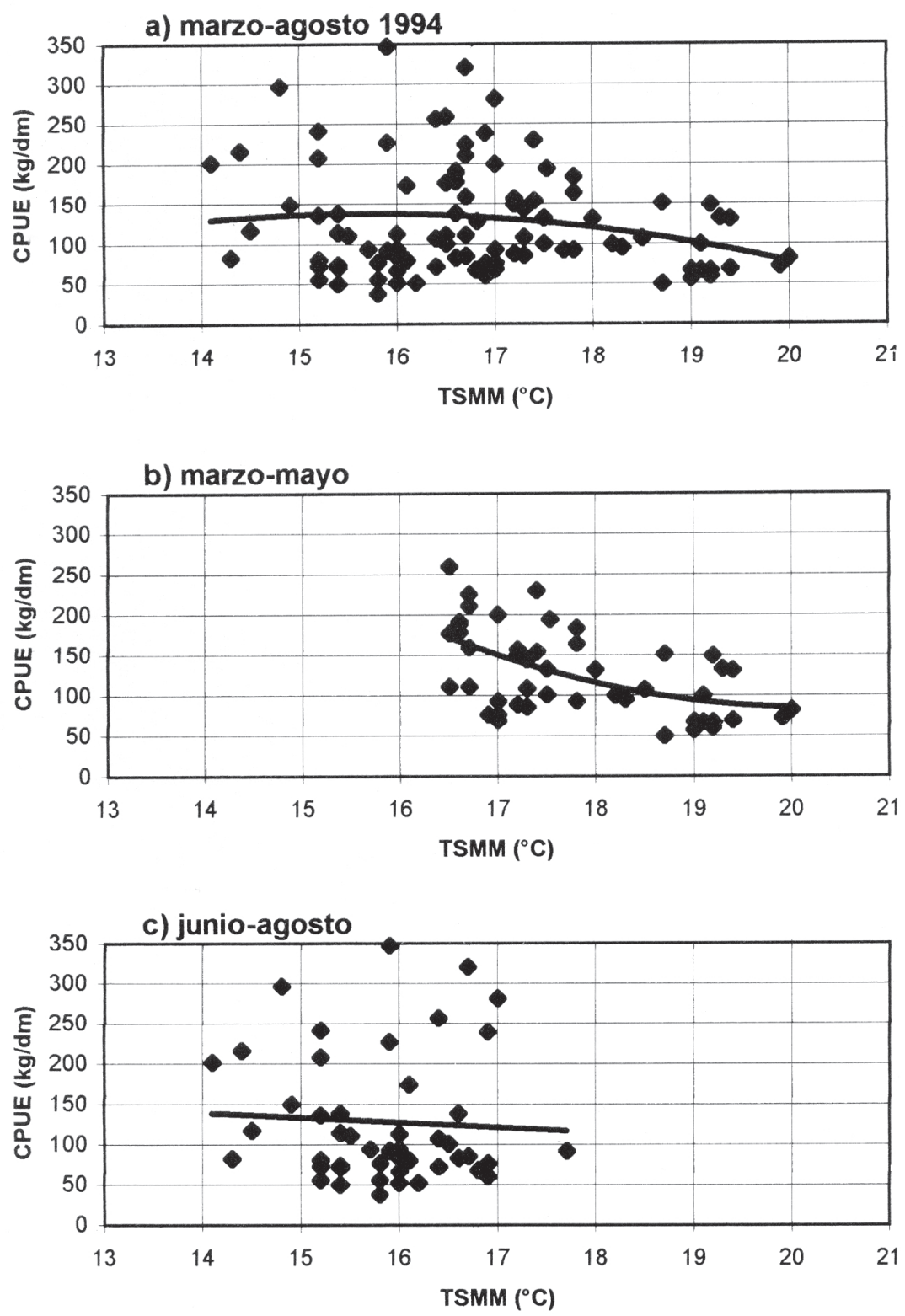

Figura 6. Registros diarios de CPUE $(\mathrm{kg} / \mathrm{dm})$ y TSMM $\left({ }^{\circ} \mathrm{C}\right)$ por períodos de 1994. Figure 6. Daily registrations of CPUE (kg/sea day) and MSST $\left({ }^{\circ} \mathrm{C}\right)$ for 1994 periods. 

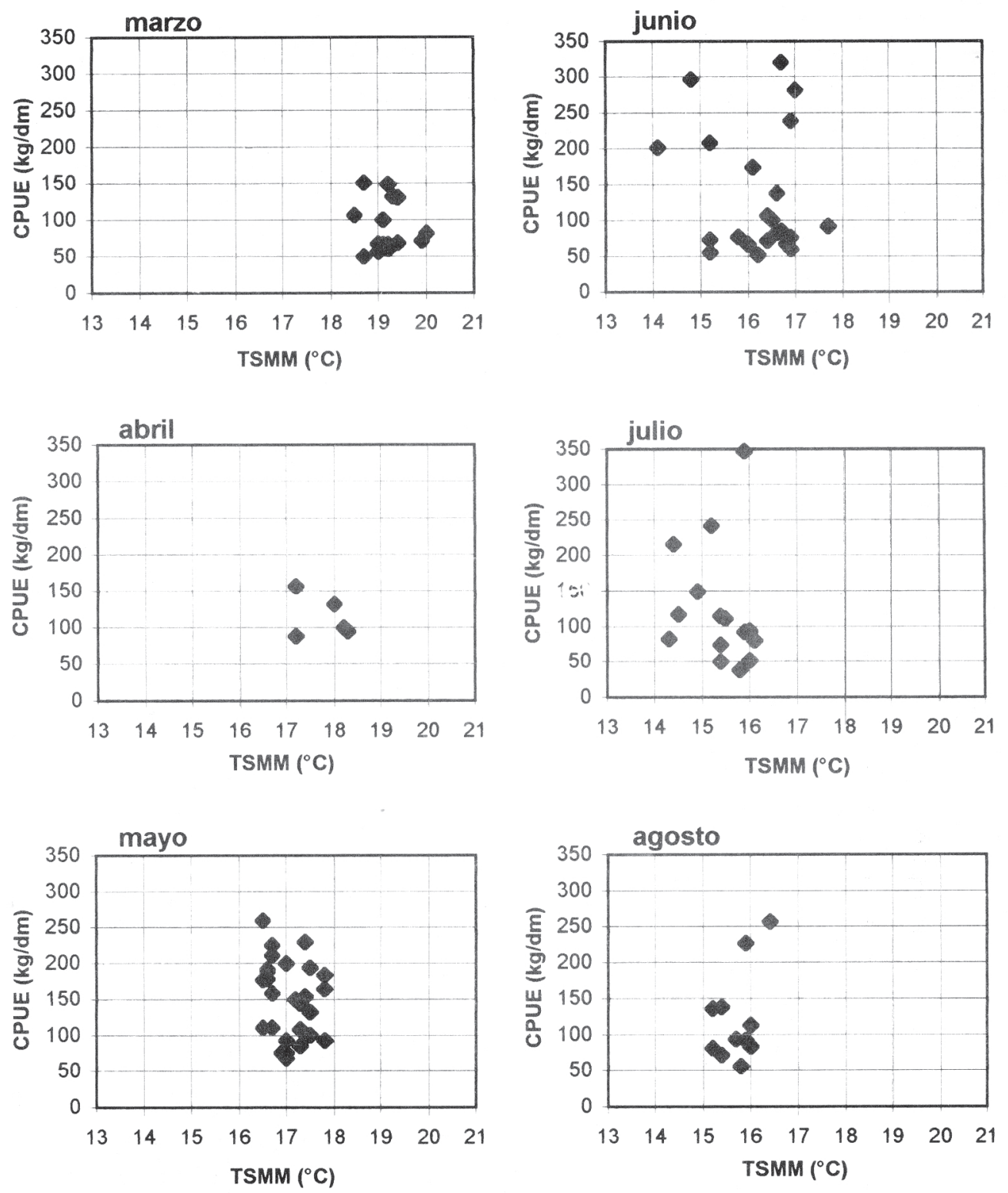

Figura 7. Registros diarios de CPUE (kg/dm) y TSMM $\left({ }^{\circ} \mathrm{C}\right)$ de marzo a agosto de 1994.

Figure 7. Daily registrations of CPUE (kg/sea day) and MSST $\left({ }^{\circ} \mathrm{C}\right)$ from March to August of 1994. 


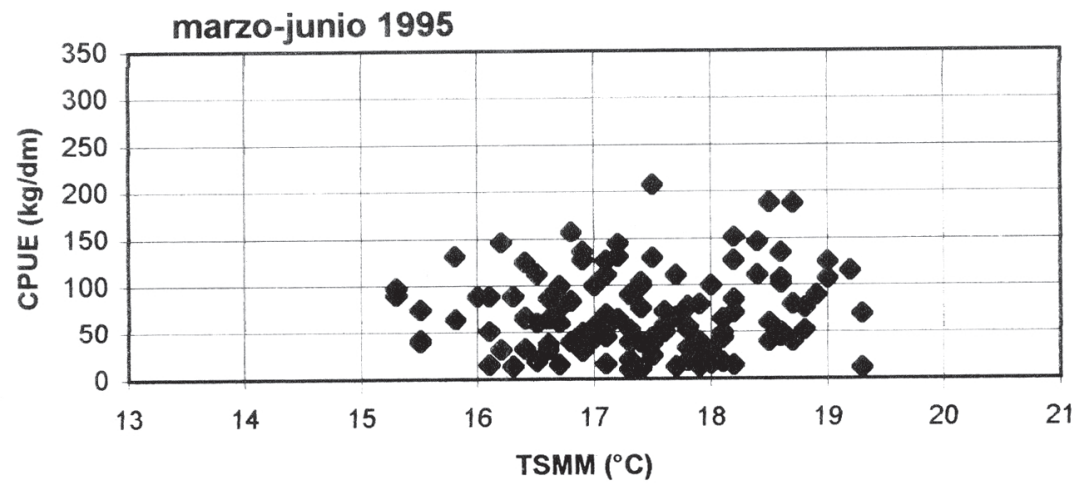

Figura 8. Registros diarios de CPUE $(\mathrm{kg} / \mathrm{dm})$ y TSMM $\left({ }^{\circ} \mathrm{C}\right)$ durante marzo-junio 1995.

Figure 8. Daily registrations of CPUE (kg/sea day) and MSST $\left({ }^{\circ} \mathrm{C}\right)$ during March-June 1995.
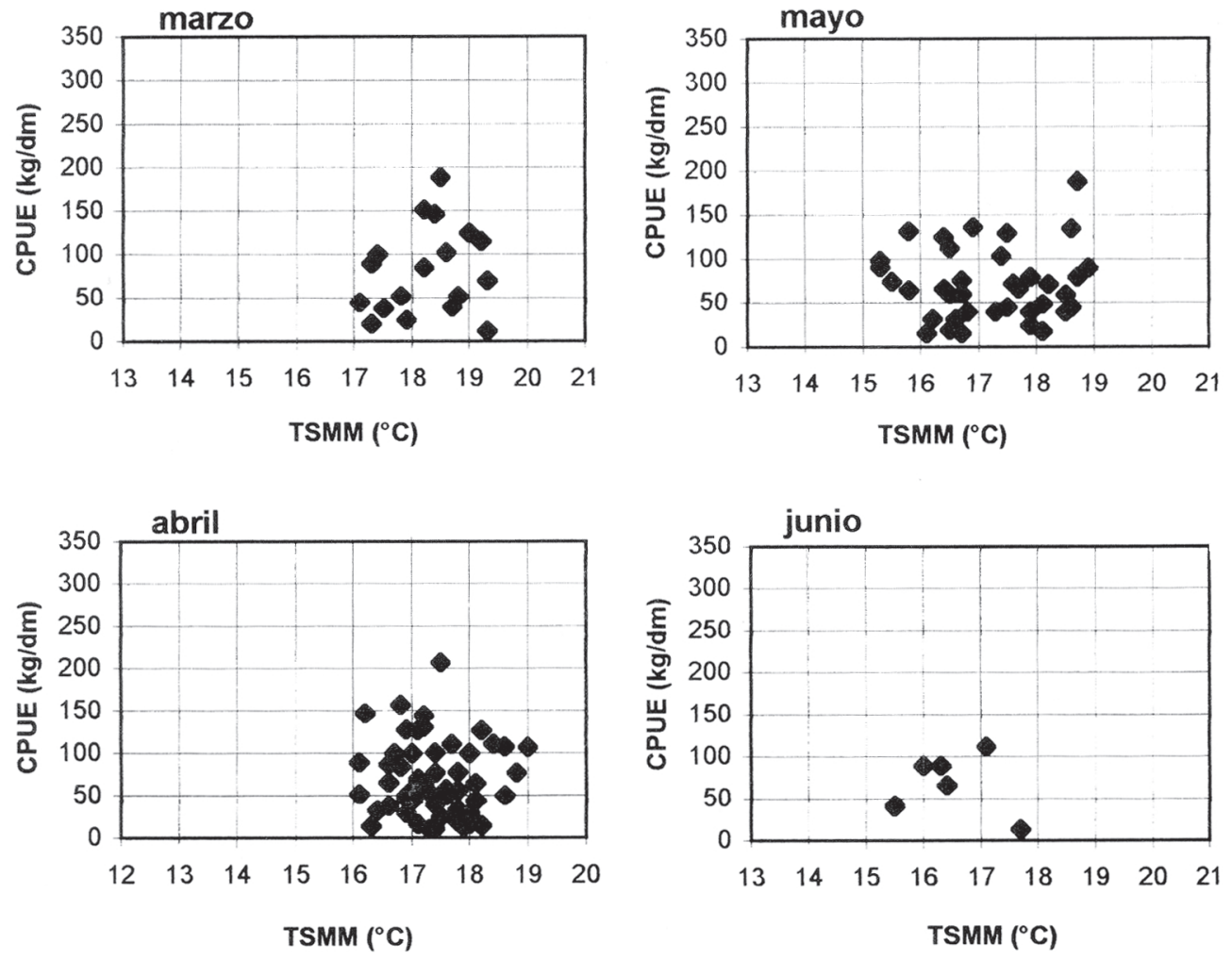

Figura 9. Registros diarios de CPUE (kg/dm) y TSMM $\left({ }^{\circ} \mathrm{C}\right)$ de marzo a junio 1995.

Figure 9. Daily registrations of CPUE (kg/sea day) and MSST $\left({ }^{\circ} \mathrm{C}\right)$ from March to June 1995. 
a) marzo-agosto 1994

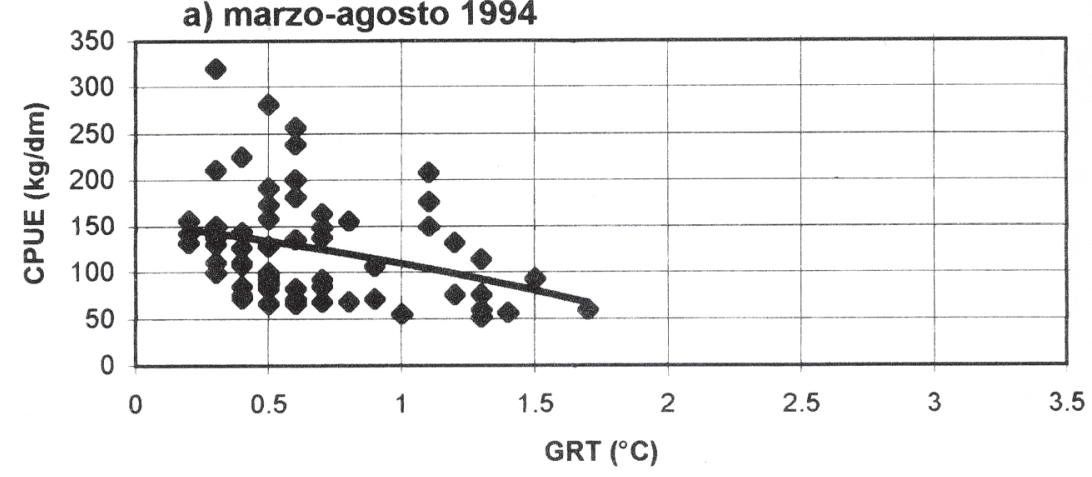

b) marzo-junio 1995

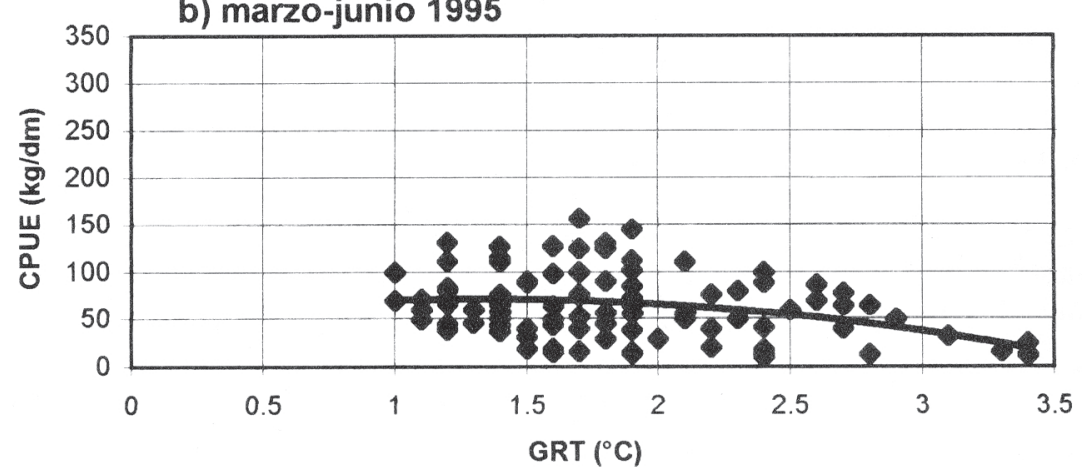

Figura 10. Registros diarios de CPUE $(\mathrm{kg} / \mathrm{dm})$ y GRT $\left({ }^{\circ} \mathrm{C}\right)$ durante marzo-agosto 1994 y marzo-junio 1995. Figure 10. Daily registrations of CPUE $(\mathrm{kg} / \mathrm{dm})$ and TGR $\left({ }^{\circ} \mathrm{C}\right)$ during March-August 1994 and March-June 1995.

y de calamar (Loligo gahi), además de restos de peces óseos y de material digerido. Por otra parte, asociado al comportamiento migratorio del jurel (Serra, 1991), la pesquería que se realiza sobre este recurso en la zona centro-sur de Chile presenta una clara estacionalidad, con rendimientos intermedios en enero-abril, máximos en mayo-agosto y mínimos en septiembre-diciembre (Yáñez et al., 1996). Esta estacionalidad del jurel resulta bastante parecida a las variaciones mensuales de los desembarques de pez espada en la zona de estudio (Tabla 5).

\section{REFERENCIAS}

Bakun, A. 1994. Climate change and marine populations: interactions of physical and biological dynamics. In: Workshop on the Scope, Significance, and Policy Implications of Global Change and Marine Enviroment. University of Rhode Island, USA, 14-17 May, 16 pp.

Barbieri, M.A., M. Bravo, M. Farías, A. González, O. Pizarro y E. Yáñez. 1995. Fenómenos asociados a la estructura térmica superficial del mar observados a través de imágenes satelitales en la zona norte de Chile. Invest. Mar., Valparaíso, 23: 99-122.

Barbieri, M.A., F. Naranjo, E. Yáñez, M. Farías, G. Daneri y P. Rojas. 1987. La pesquería artesanal de atún aleta larga (Thunnus alalunga) en la zona de Valparaíso $\left(33^{\circ} \mathrm{S}-72^{\circ} \mathrm{W}\right)$ y el satélite NOAA. Invest. Mar., Valparaíso, 15: 41-61.

Barbieri, M.A., E. Yáñez, L. Ariz y A. González. 1990. La pesquería del pez espada: tendencias y perspectivas. In: M.A. Barbieri (ed). Perspectivas de la Actividad Pesquera en Chile, Escuela de Cien- 
cias del Mar, UCV, Valparaíso, pp. 195-214.

Barbieri, M.A., E. Yáñez, V. Correa y C. Bernal. 1995/96. Proyecto SATAL II: La pesca desde el cielo. In: Tecnigraf (ed.) Catálogo de la Industria Pesquera y Acuicultura en Chile, Escuela de Ciencias del Mar, UCV, Valparaíso, Vol. 9 (3): 3-10.

Eastman, J.R. 1995. IDRISI for windows: user's guide. Clark University, MA-USA, 372 pp.

FAO. 1985-93. Anuarios estadísticos de pesca: capturas y desembarques. Fishery Information, Data and Statistics Service, Fisheries Department, FAO, Rome, Italy.

González, A. 1993. Distribución espacio-temporal de la pesquería artesanal de pez espada (Xiphias gladius) desarrollada por la flota de Valparaíso y variaciones ambientales entre 1987 y 1991. Tesis, Escuela de Ciencias del Mar, UCV, Valparaíso, 103 pp.

IFOP, 1996. Seguimiento de las principales pesquerías chilenas, 1995. Instituto de Fomento Pesquero, Valparaíso, 272 pp.

Laurec, A. y J.C. Le Guen. 1981. Dynamique des populations marines exploitées. CNEXO, France, Rapp. Scient. et Tech. No45, 117 pp.

Maravelias, C.D. y D.G. Reid. 1995. Relationship between herring (Clupea harengus, L.) distribution and sea surface salinity and temperature in the northern North Sea. Sci. Mar., 59 (3-4): 427-438.

OPI Inc. 1994. Equipos y servicios para localizar peces. In: Lindgren-Pitman Inc. (eds.) Catálogo Palangrero Completo, p. 49.

Pettigiani, E., H. Karszenbaum y M. Mejali. 1992. Análisis de imágenes satelitarias de temperaturas superficiales mediante funciones empíricas ortogonales en la zona común de pesca argentinouruguaya. Rev. SELVER, 8(1): 43-48.

Power, J.H. y L.N. May. 1991. Satellite observed seasurface temperatures and yellowfin tuna catch and effort in the Gulf of Mexico. Fish. Bull., 89(3): 429439.

Reddy, R., V. Lyne, R. Gray, A. Easton y S. Clarke. 1995. An application of satellite-derived sea surface temperatures to southern bluefin tuna and albacore off Tasmania. Australis. Sci. Mar., 59 (3-4): 445454.

SERNAP. 1985-95. Anuarios estadísticos de pesca. Ministerio de Economía, Servicio Nacional de Pesca, Valparaíso, Chile.

Serra, R. 1991. Important life history aspects of the chilean jack mackerel, Trachurus symmetricus murphyi. Invest. Pesq. (Chile) 36: 67-83.

Yáñez, E., M.A. Barbieri, C. Canales, V. Correa, M. Donoso, A. González, B. Leiva y A. Montiel. 1994. Development and satate of art of the swordfish fishery in Chile. Inter. Symp. on Pacific Swordfish, Ensenada (B.C.), México, december 1114. Fishery Bulletin, en prensa.

Yáñez, E., V. Catasti, M.A. Barbieri y G. Böhm. 1996. Relaciones entre la distribución de recursos pelágicos pequeños y la temperatura superficial del mar registrada con satélites NOAA en la zona central de Chile. Invest. Mar., Valparaíso, 24: 107-122.

Yáñez, E., A González y M.A. Barbieri. 1995. Estructura térmica superficial del mar asociada a la distribución espacio-temporal de sardina y anchoveta en la zona norte de Chile entre 1987 y 1992. Invest. Mar., Valparaíso, 23: 123-147. 